\title{
High Resolution Remote Sensing Images Based Catastrophe Assessment Method
}

\author{
Qi Wen et al.* \\ National Disaster Reduction Center of China \\ China
}

\section{Introduction}

In recent years, there seems to be more and more occurrences of natural disasters happening around the world due to abnormal climate change. To deal with natural disasters, disaster assessment technology will provide technical support and help facilitate decision making for disaster relief, disaster prevention and reduction, post-disaster recovery and reconstruction (The six editing room of Press of China Standards, 2010). Airborne remote sensing and satellite remote sensing, which feature no time limitation, no geographical restriction, wide coverage and high accuracy, are widely used in disaster assessment scenario, because they can provide prompt and accurate information (Xie \& Zhang, 2000). After several earthquakes happened around China (Xingtai, Haicheng, Tangshan, Longling, Datong) during 1970s and 1980s, China had widely implemented airborne remote sensing photography and seismic damage interpretation (Zhang, 1993). Remote sensing had also played an important role in disaster assessment of recent occurring disasters, including Wenchuan Earthquake, Yushu Earthquake, Zhouqu Debris flow and Yingjiang Earthquake (Chen et al., 2008; Shi et al., 2010). This chapter will mainly discuss the catastrophe assessment method and technical flow used by National Disaster Reduction Center of China (NDRCC) during Wenchuan Earthquake(2008), Yushu Earthquake(2010), Zhouqu Debris Flow(2010). Further discussion and advises are also given.

\section{The flow of catastrophe assessment method}

Traditionally, catastrophe assessment process can be divided into three major steps: disaster scope assessment, physical quantity assessment and direct economic losses assessment. In addition, two assessment processes: rapid disaster assessment and ground investigation process are needed to supplement the major steps. Rapid disaster assessment is usually carried out to preliminarily judge the disaster condition after the disaster occurred. The reported data from Rapid Disaster Assessment, combined with that from following Disaster Scope Assessment, are integrated to have an overview of disaster scope and extent. Another supplementary process, Ground Investigation Process, is usually carried out to cross-

\footnotetext{
*Yida Fan, Siquan Yang, Shirong Chen, Haixia He, Sanchao Liu, Wei Wu, Lei Wang, Juan Nie, Wei Wang, Baojun Zhang, Feng Xu, Tong Tang, Zhiqiang Lin, Ping Wang and Wei Zhang National Disaster Reduction Center of China, China
} 
validate disaster condition after Rapid Disaster Assessment process. The rapid disaster assessment result, ground investigation data, combined with high resolution remote sensing data will provide a detailed comprehensive assessment report of disaster condition. Figure 1 illustrates the flow of catastrophe assessment method.

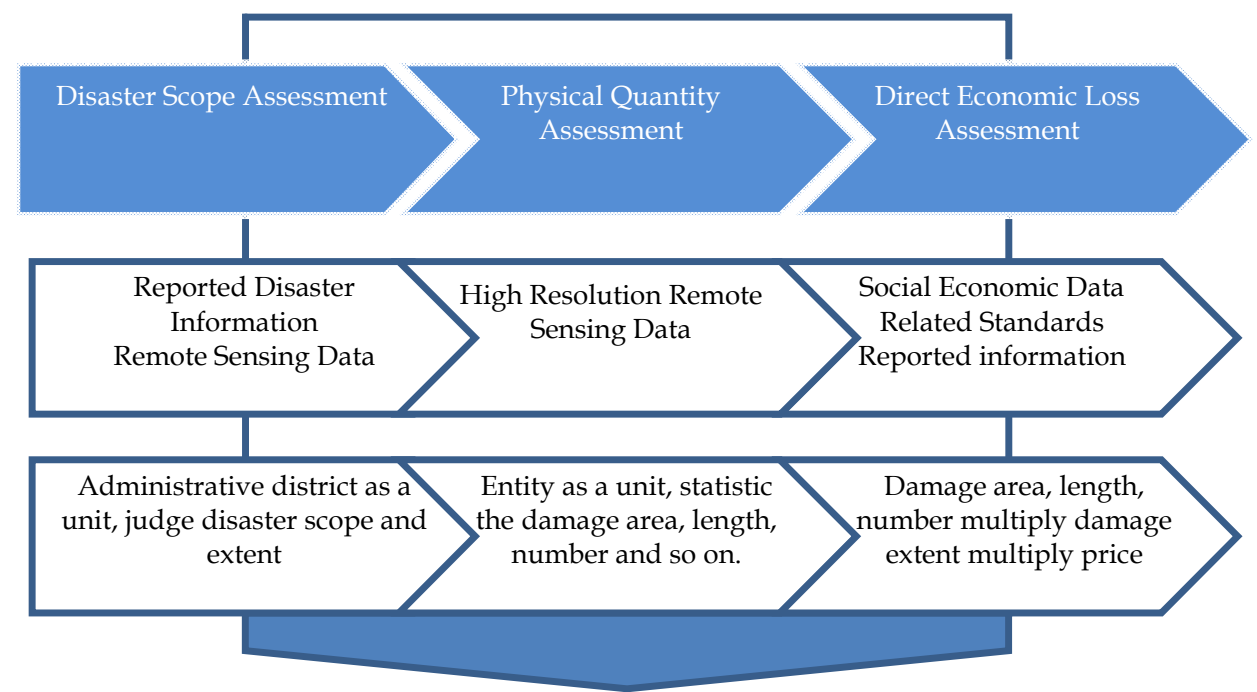

Fig. 1. The flow of catastrophe assessment method

\subsection{Preliminary judgment of disaster condition}

When the disaster happens, the remote sensing system will response immediately. By comparing pre-disaster and post-disaster high resolution remote sensing images, data on damage of transportation lines, houses, variation of terrain will be generated, and preliminarily overview of damage and disaster trend will be concluded based on these data.

\subsection{Ground investigation}

When the disaster situation is stable, according to preliminary judgment result, an expert investigation group will be sent to investigate in-field the disaster situation of sample region. Prior to ground investigation, the disaster region should be partitioned as multilevel grids in high-resolution remote sensing images. The first level partitioning is to partition the remote sensing images to functional zone according to administrative district, based on which the second level partitioning is to partition each functional zone to smaller unit, named "Entity", according to street in order to facilitate the ground investigation. The third level partitioning is to partition the "Entity" to even smaller grid unit according to house and parcel of rice field. All the grids are indexed, so that the investigation team members can fill out the corresponding forms. Investigation team uses Ground Disaster Information Collection System (Figure 2) to retrieve disaster information of $3^{\text {rd }}$ level grid unit, including number of houses and their floors, estimated construction cost, and general information of $1^{\text {st }}$ level unit, including affected population, damage extent and field photos. This information is collected and sent to the assessment team in NDRCC. 


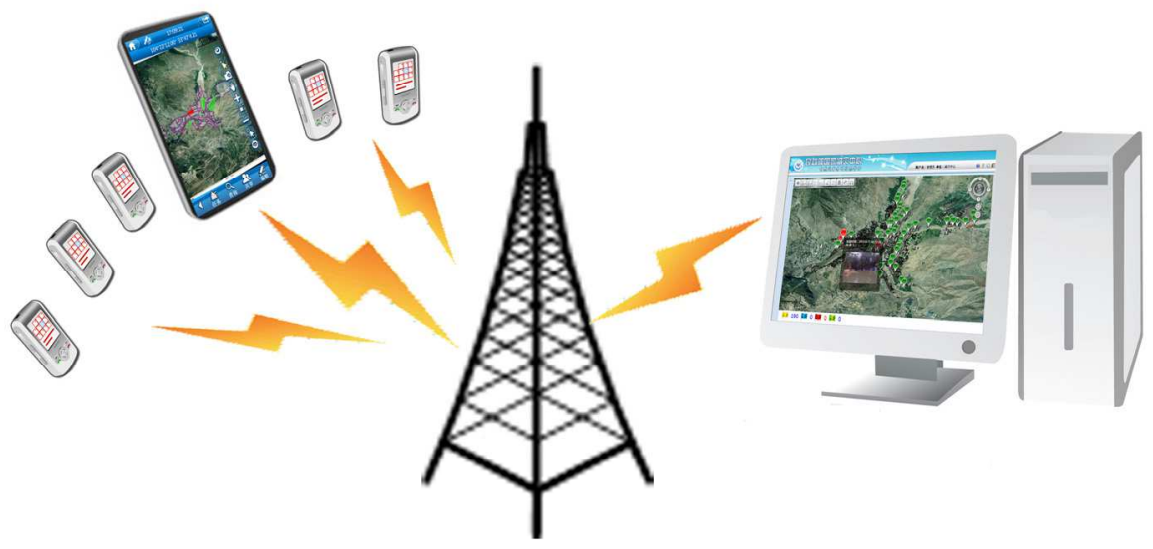

Fig. 2. Ground Disaster Information Collection System

Ground Disaster Information Collection System is a GIS software with the client-server architecture. The client side implemented in mobile phone is used to collect text and picture disaster information, label the position and send information to the sever side. The server side receives information from client side, interprets it and stores it to database.

\subsection{Disaster scope assessment}

When the disaster situation is stable, data reported by local government, assessment results generated by investigation expert group, interpreted data from remote sensing images are integrated and analyzed together to implement disaster scope assessment for sample regions. Regression relations between the sample regions and the entire disaster area are then established. Also, damage assessment data in adjacent regions are interpolated so as to generalize assessment of the whole area based on that of sample region.

In the case of an earthquake, disaster loss assessment is graded using Comprehensive Disaster Index. Disaster scope and extent of loss are assessed as a unit of administrative district(such as "county" in China). The Comprehensive Disaster Index is usually calculated as a weighted sum of the average seismic intensity, the toll of death and missing, the rate of number of death and missing per ten thousands persons, the number of collapsed houses, the rate of number of collapsed houses per ten thousands people, the geological disaster risk, and the rate of number of relocated person per ten thousand people.

$$
D I=\sum\left(f_{k} \times D I_{k}\right)
$$

$D I_{k}$ is the $k^{\text {th }}$ normalized single indicator:

$$
D I_{k}=\left[D I_{k}-\min \left(D I_{k}\right)\right] /\left[\max \left(D I_{k}\right)-\min \left(D I_{k}\right)\right]
$$

$f_{k}$ is the $\mathrm{k}^{\text {th }}$ weight, and should be adjusted according to the specific condition of the disaster. 
Average seismic intensity can be calculated by weighted sum of rates of different seismic intensity level for different area:

$$
I=\sum\left(I_{i} \times S_{i} / S\right)
$$

$I_{i}$ is the intensity level. $S_{i} / S$ is the rate of different seismic intensity level for different area; the toll of death and missing is the number of dead and missing persons in each county; number of collapsed houses is counted separately for different counties; geological disaster risk is calculated as a weighted sum of number of endangered residential areas, broken roads, blocked rivers, collapsed bridges and reservoirs. The rate of number of relocated per ten thousands of persons is calculated based on the base household population of each county.

\subsection{Physical quantity assessment}

The physical quantity assessment is carried out based on the previous data gathered in the first step of Disaster Scope Assessment. Based on extensive research and practical work experiences, NDRCC has established NNDDCA (the National Natural Disaster Damage Comprehensive Assessment Framework). Disaster loss is classified as five dimensions, and further divided to two hundred and twenty nine indicators. The five dimensions include: population loss, economic losses, residents' housing and property damage, national economy and industry loss, government offices and social undertakings loss. Several indicators, which are suitable to be assessed in remote sensing images, are first selected from the two hundred and twenty nine indicators and the damage of which is then assessed using artificial visual interpretation method and automatically machine recognition technology. The remote sensing index framework is then established.

One thing to notice is that, the affected population is not included in the remote sensing assessment index framework, and the economic losses can be statistically calculated from residents' housing and property damage, national economy and industry loss, government offices and social undertakings loss. The losses of residents' property are also not included in the remote sensing assessment index framework.

According to the characteristics of remote sensing technology, housing of three categories of statistical objects is classified as housing type; select specific object from agriculture, industry and services of state-owned enterprises; select water conservancy, environment, public facilities and other departments from government offices and social undertakings. Specific objects in the three categories can be divided into three new categories of remote sensing index of physical quantity damage assessment: housing and buildings, important infrastructure and natural resources. The first category, housing and buildings, includes building, bungalow, chimney and water tower. In the second category, important infrastructures include transportation, municipal, power, water, telecommunication and radio communication, pipeline facilities, etc., natural resources include land resources and water resources. Table 1 below shows a selection of assessment indicators.

In our case, data extracted from high-resolution remote sensing images in the step of Physical Quantity Assessment is usually brought to the decision-making chain as major information resource. By using pre-disaster and post-disaster UAV and airborne highresolution remote sensing images collected from members of NDRCC, we have 


\begin{tabular}{|c|c|c|c|}
\hline & & & Building \\
\hline & Housing and buil & dings & Bungalow \\
\hline & & & \\
\hline & & & Provincial road \\
\hline & & Transportation & County road \\
\hline & & infrastructure & Bridge \\
\hline & & & Railway \\
\hline & & & airport pavement \\
\hline & & & Municipal road \\
\hline & & Municipal & Public traffic facility \\
\hline & & infrastructure & Urban green land \\
\hline sensing & Important & & Street lamp \\
\hline indexes of & infrastructures & Power facility & Power generation, substation facility \\
\hline physical & & I Ovver tactiny & Overhead power line \\
\hline damage & & & reservoir \\
\hline assessment & & Water conservancy & channel \\
\hline & & facility & dam \\
\hline & & & embankment \\
\hline & & telecommunication & emission station \\
\hline & & $\begin{array}{l}\text { communication } \\
\text { facility }\end{array}$ & transmission line \\
\hline & & Pipeline resources & Overhead and ground pipeline \\
\hline & & & Farmland \\
\hline & & Land resources & Woodland \\
\hline & Natural resources & & Building land \\
\hline & & & River \\
\hline & & & Lake \\
\hline
\end{tabular}

Table 1. Remote sensing indexes of physical quantity damage assessment

implemented disaster targets recognition and change detection, through which disaster data is extracted and integrated. The data includes number and area index of houses, number and length of roads, number and area index of power facilities, water conservation facilities, and communication stations, municipal utilities, and land resources.

\subsection{Direct economic losses assessment}

Based on physical quantity assessment results and related standards, Direct Economic Loss is assessed for houses, infrastructure of government, industry, and personal property within disaster areas. For example, the economic loss of a building can be calculated by multiplying 
build-up area, damage rate, and unit price. The damage rate is usually calculated using damage extent grading method. Other indicators follow the same method in calculating that of building.

\section{Case studies of remote sensing catastrophe assessment}

Catastrophe afflicted areas usually have complex terrain and frequently changing weather in a short time after the disaster, which makes earth observation technology one of the best methods for disaster emergency monitoring and disaster assessment due to the acquisition capability of high resolution images. In this section, three cases in China will be discussed in detail to illustrate the Disaster Assessment Technology NDRCC had used: Wenchuan Earthqueake, Yushu Earthquake, and Zhouqu Debris Flow Disaster. During Wenchuan Earthquake in May 2008, we used high resolution airborne remote sensing images, reported data collected by local government and ground investigation data in combination for Disaster Scope Assessment (Fan et al., 2008a); during Yushu Earthquake in April 2010, we implemented housing damage assessment (Yang et al., 2011); during Zhouqu Debris Flow Disaster in August 2010, we implemented Physical Quantity Assessment and Direct Economic Loss Assessment (Qi et al., 2011). The Physical Quantity Assessment is implemented based on disaster scope assessment result with indicators like houses and building, important infrastructure, land resources, and the Direct Economic Loss Assessment is implemented based on physical quantity assessment result.

\subsection{Wenchuan earthquake}

On May 12th 2008 , an earthquake of magnitude 8.0 Richter occurred in the countryside of Wenchuan, Sichuan province, China. The maximum seismic intensity was 11 degree which is higher than that of Tangshan Earthquake (7.8 Richter). Aftershocks frequently occurred and the largest one was of magnitude 6.4 Richter. Four hundred and seventeen counties out of ten provinces (Sichuan, Gansu, Shanxi, Chongqing, Guizhou, Yunnan, Henan, Hubei, Shanxi, Hunan) suffered from this disaster, leading to 69197 deaths, 18289 missing and 374000 injuries by July $13^{\text {th }} 2010$. The highly affected areas are most in mountainous valley where traffic was not convenient. The earthquake and following aftershock wrecked the fragile transportation and communication facilities, making disaster relief a very difficult job since rescue personnel, supplies, vehicles and large-scale disaster rescue equipments couldn't access the disaster scene in time.

\subsubsection{Preliminary judgment of disaster scope}

A seismic intensity distribution map was immediately made after the earthquake using empirical data from USGS (Figure 3). Results showed that the maximum intensity was beyond 9 degrees. Then, data of population and areas of affected towns and counties in the affected regions is calculated according to the map.

\subsubsection{Remote sensing assessment of housing damage}

Short after the earthquake in Wenchuan, we rapidly collected 1277 remote sensing images captured by 24 satellites from 12 countries using the International Charter "SPACE AND MAJOR DISASTERS" and domestic satellites data sharing mechanism. Several airplanes of 


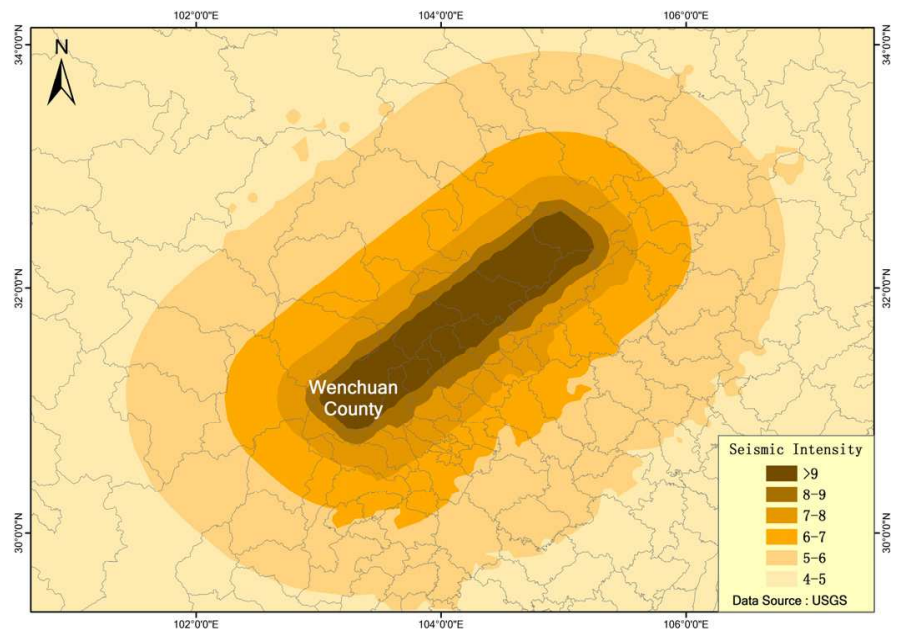

Fig. 3. Seismic intensity distribution map

National Administration of Surveying and Chinese Academy of Sciences flew to affected area to take airborne remote sensing image, in a resolution of $0.5 \mathrm{~m}$ and $2 \mathrm{~m}$.

Take the indicator of houses for example. With the help of remote sensing images, damage condition of houses in satellite-covered regions was estimated. For uncovered regions, damage condition of houses was estimated by proportional spatial extrapolation and interpolation based on data from satellite-covered regions in a unit of village or town. Based on destruction probability of general fortified buildings, combined with the seismic intensity data, the relationship between collapse rate and damage rate was calculated. Damage condition of housing in affected region was then estimated. Figure 4 illustrates the flow of damage assessment process for the indicator of houses during Wenchuan Earthquake (Fan

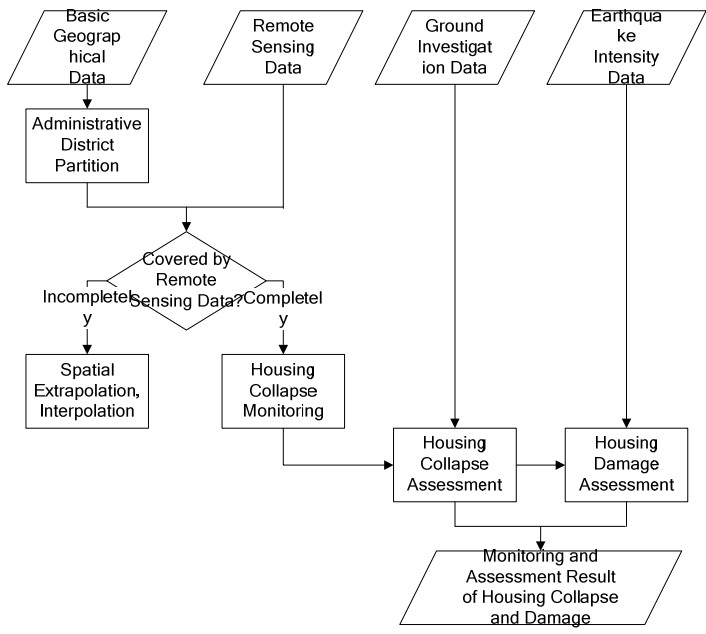

Fig. 4. The flow of collapse and damage assessment process for houses 
et al., 2008b). Figure 5, 6, and 7 show the damage assessment map of sample regions: Maoxian County, Qingchuan County and the city of Dujiangyan. Figure 8 demonstrates the comprehensive assessment result of damage of the whole disaster area for single indicator of houses.

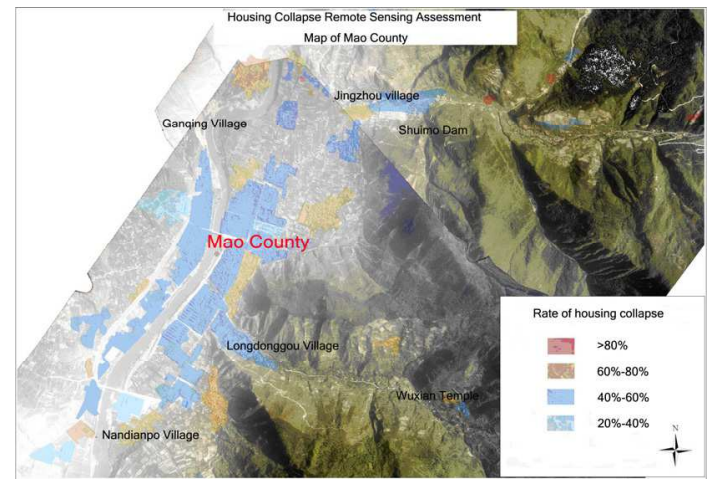

Fig. 5. The damage assessment result of Maoxian County for houses.

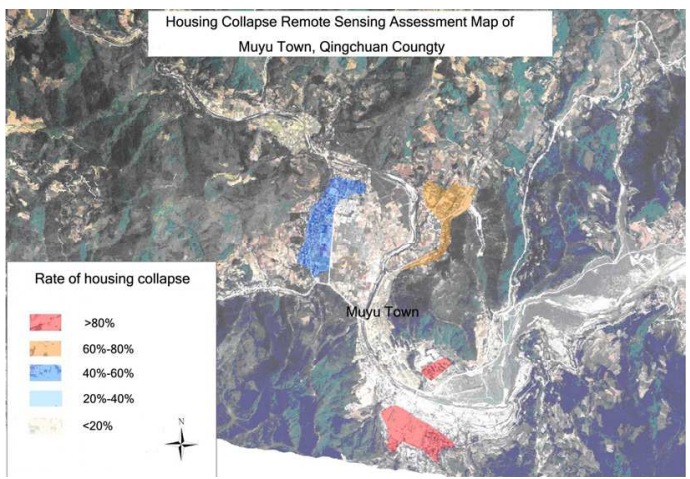

Fig. 6. The damage assessment result of Qingchuan County for houses.

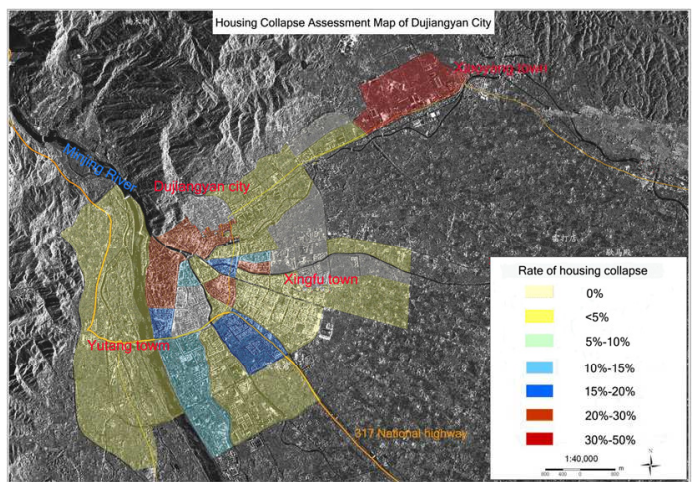

Fig. 7. The damage assessment result of Dujiangyan City for houses. 


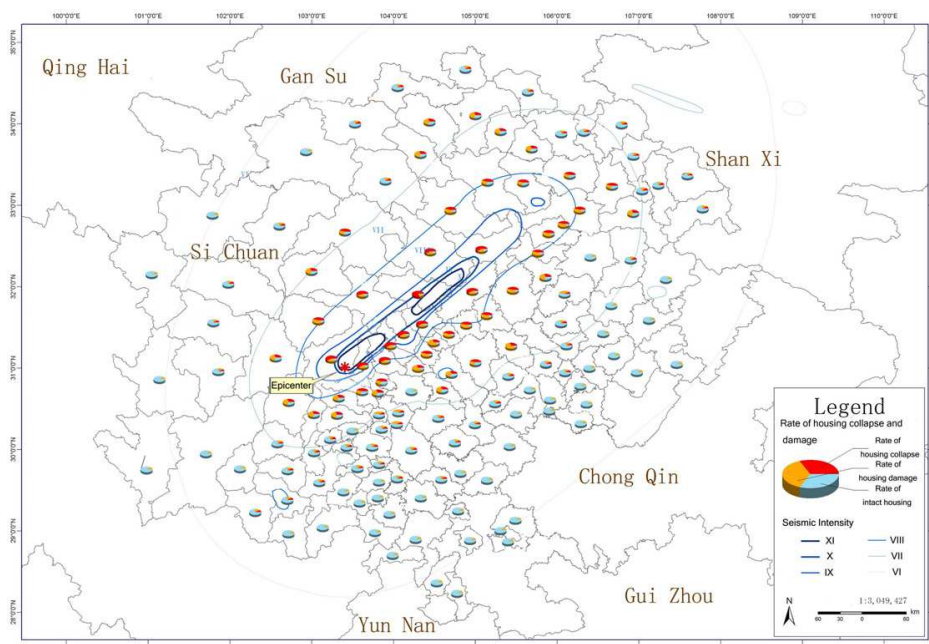

Fig. 8. Comprehensive assessment map of damage for houses

\subsubsection{Disaster monitoring}

In the following days after the quake, we continually and extensively monitored traffic, main national roads and settlements in disaster area to fast and accurately identify and locate traffic jam and landslide with the help of high-resolution remote sensing images.

EROS-B satellite image on May 15th illustrates several traffic jams occurred along 213 and 317 national highway in suburban area around Wenchuan due to secondary disaster landslide (Figure 9).

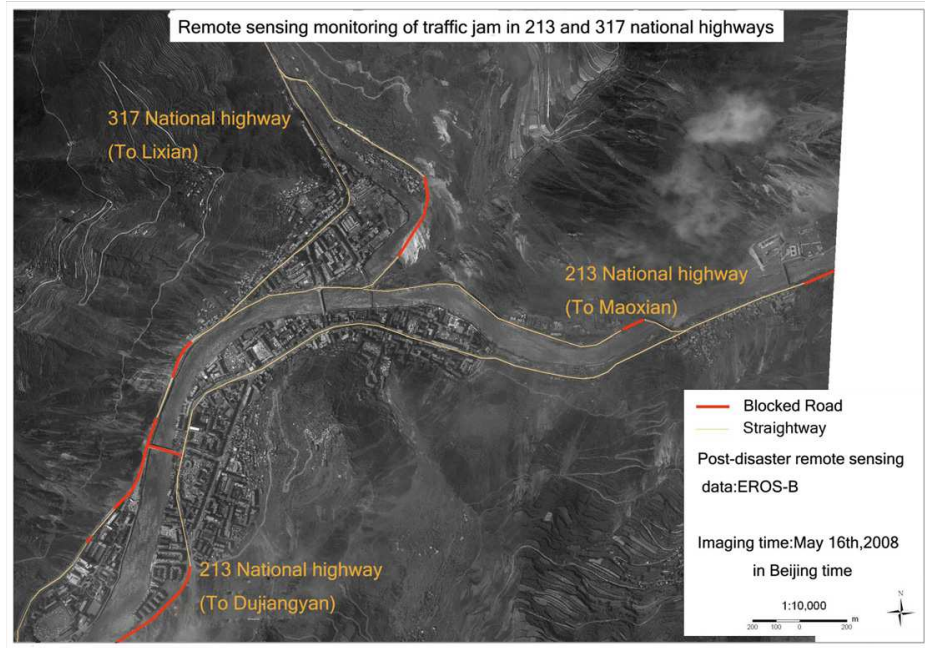

Fig. 9. Remote sensing image of the area along 213 and 317 national highways in the countryside of Wenchuan. Be noticed traffic jams are spotted with red lines 
Quickbird satellite image on May 16 th illustrates 5 landslides happened in a 2-kilometre diameter area around Yongan County, which seriously interrupted traffic (Figure 10).

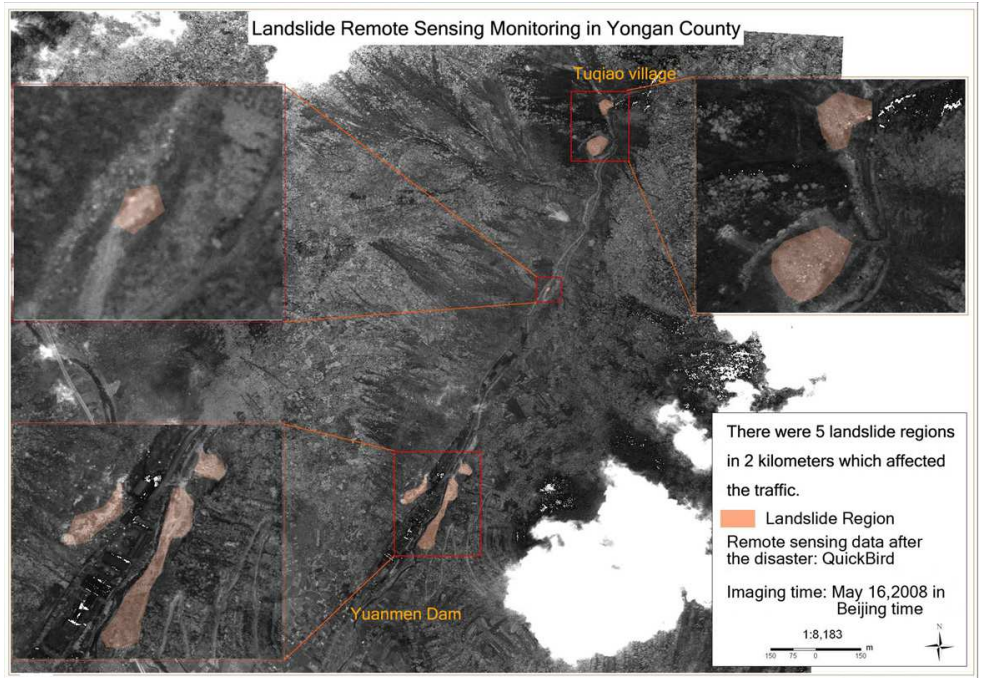

Fig. 10. Remote sensing image from Quickbird satellite about landslide around Yongan County

Comparing EROS-B satellite image of $0.7 \mathrm{~m}$ on May $27^{\text {th }}$ and airborne remote sensing image of $0.5 \mathrm{~m}$ resolution on May $18^{\text {th }}$, about 10 large refugee settlements distributed along both sides of urban main road in Qingchuan County (Figure 11), which increased significantly in ten days.

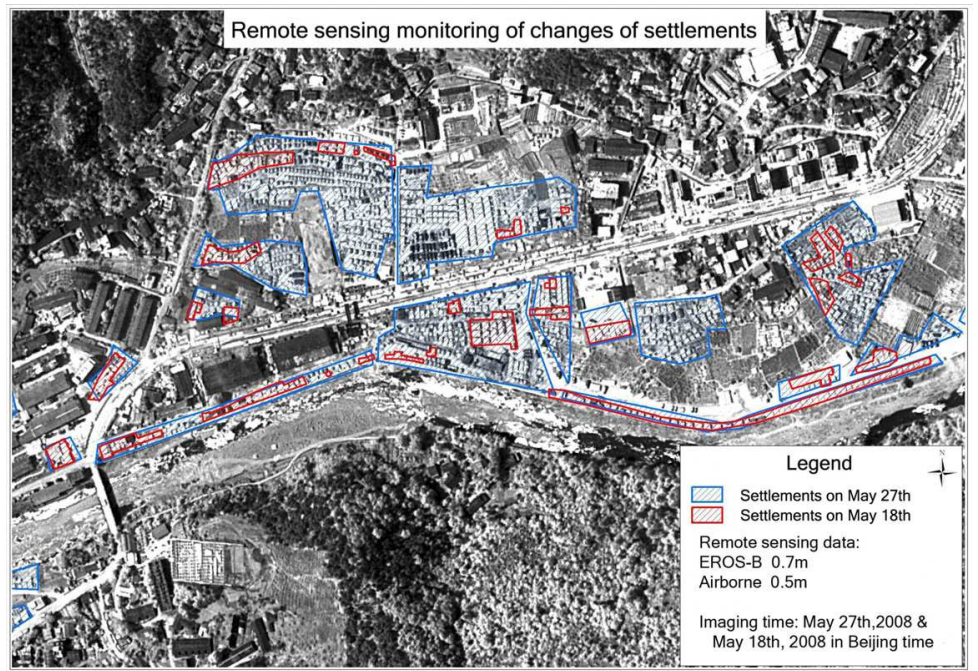

Fig. 11. Remote sensing images about quantity increasing of refugee settlements 


\subsubsection{Disaster scope assessment results}

Combined with remote sensing interpretation results, ground investigation information and reported data from local government, we built Comprehensive Disaster Index (CDI) for Disaster Scope Assessment. The index will be demonstrated in detail as follows:

The weight of average seismic intensity was 0.3 ; the weight of rate of death and missing per ten thousands persons was 0.15 , and the total weight was 0.3 ; the weight of houses collapsed rate per ten thousands was 0.1 , and the total weight was 0.2 ; the weight for geological disaster risk was 0.1 ; the weight of relocated rate per ten thousands was 0.1 .

Disaster area was partitioned into three sub region (Figure 12): serious region, severe region, and general region. The area and CDI of serious region was around $26000 \mathrm{~km}^{2}$, and 0.4 above; the area and CDI of severe region was around $90000 \mathrm{~km}^{2}$, and between 0.15 and 0.4 ; the area and CDI of general region was around $384000 \mathrm{~km}^{2}$, and between 0.01 and 0.15 .

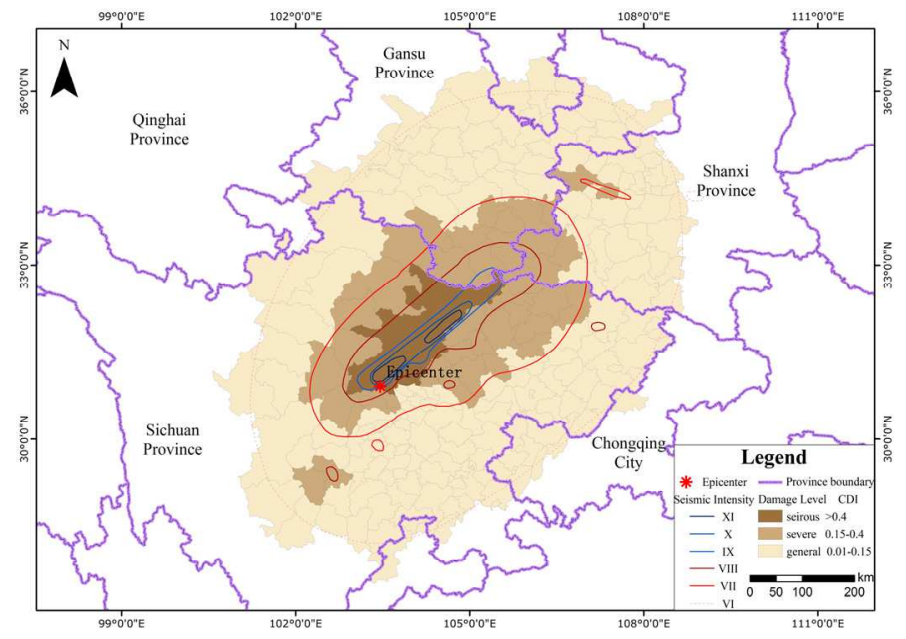

Fig. 12. Disaster scope assessment map of Wenchuan Earthquake

\subsection{Yushu earthquake}

On April 14th, 2010, a magnitude-7.1 earthquake hit Yushu County, Yushu Tibetan Autonomous Prefecture, in Qinghai Province of China. The epicentre (pointer on earth surface directly above) was located in 14-kilometre depth at 33.2 degrees north latitude, 99.6 degrees east longitude, with a seismic intensity 9-degree at maximum. Aftershocks frequently occurred with the largest one of magnitude-6.3. The earthquake wrecked Jiegu town and its surrounding area, resulted in 2220 deaths, 70 missing and 12135 injuries by p.m. 5, April 14th 2010. Many factors, such as high latitude, inconvenient traffic and cold weather, make disaster relief very difficult.

\subsubsection{Preliminary assessment}

Firstly, a seismic intensity distribution map was made by earthquake intensity empirical model according to earthquake magnitude, depth of epicentre and regional fracture zone 
distribution. Jiegu Town, Yushu County was in the hard-hit area with IX degree. Figure 13 illustrates contour of seismic intensity and terrain distribution.

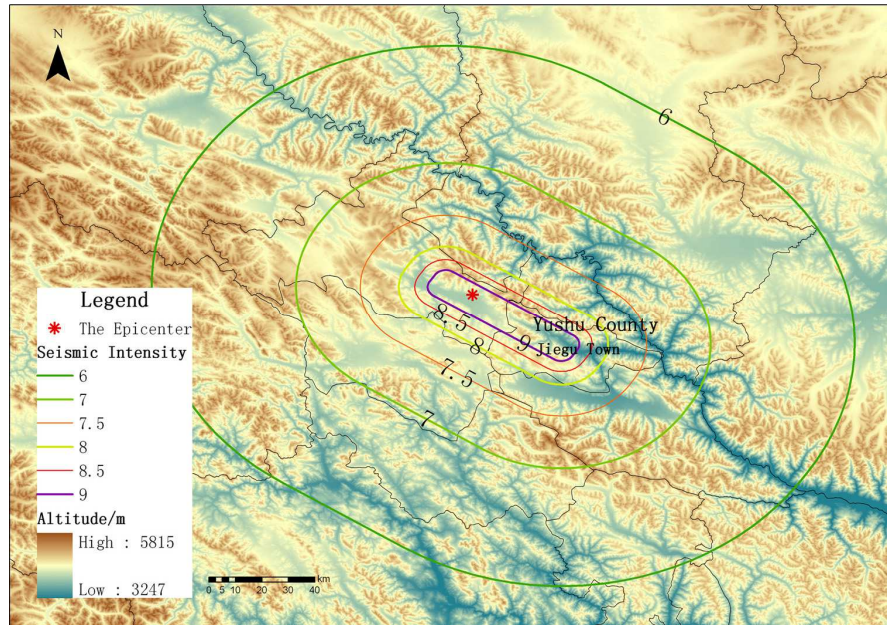

Fig. 13. Seismic intensity and terrain distribution map

By comparing pre-disaster airborne remote sensing images and post-disaster EROS-B high resolution satellite images, we analyzed the damage condition of housings, and estimated disaster scope and damage extent rapidly. Figure 14 illustrates the assessment result.

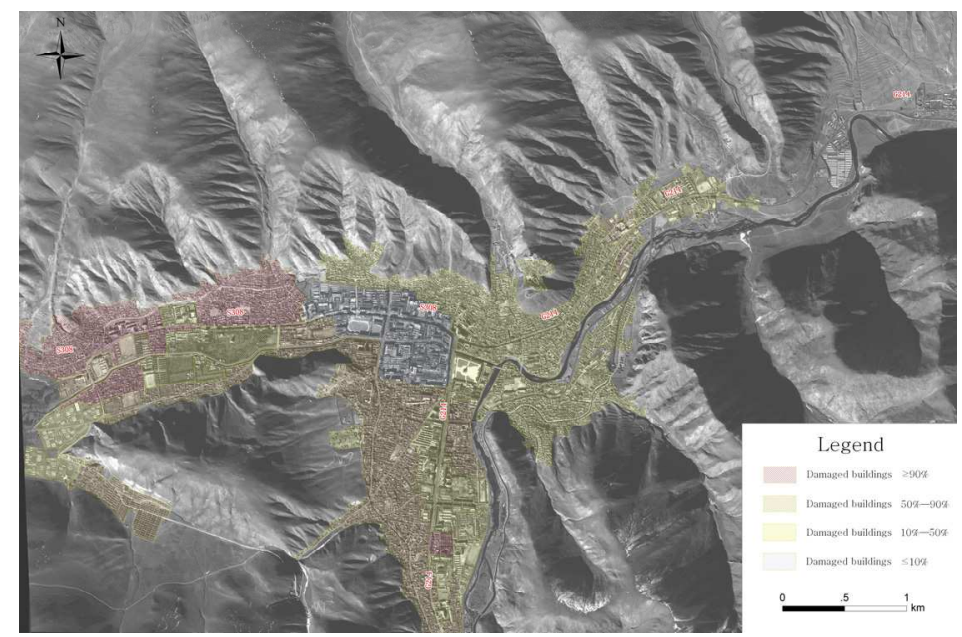

Fig. 14. Rapid assessment of disaster scope and extent of houses damage

\subsubsection{Ground investigation and comprehensive assessment}

Immediately after the quake, an airplane of Chinese Academy of Sciences (CAS) was sent to Yushu to take airborne remote sensing images. Images with a total storage of 409G and 0.4 
meter spatial resolution were acquired, covering $4500 \mathrm{~km}^{2}$ hard-hit area. Then combined with the result from preliminary assessment process, we partitioned residential region of Jiegu Town into 3-level grids according to street, function, and structure. About 685 girds of functional level were indexed.

First level (Figure 15) includes 4 categories: government office, community, industry area, and restricted area; second level (Figure 16) includes 6 categories: government office, school, general office, community, industry area, and restricted area; third level (Figure 17) includes 5 categories: building, bungalow, greenhouse, square, and stadium.

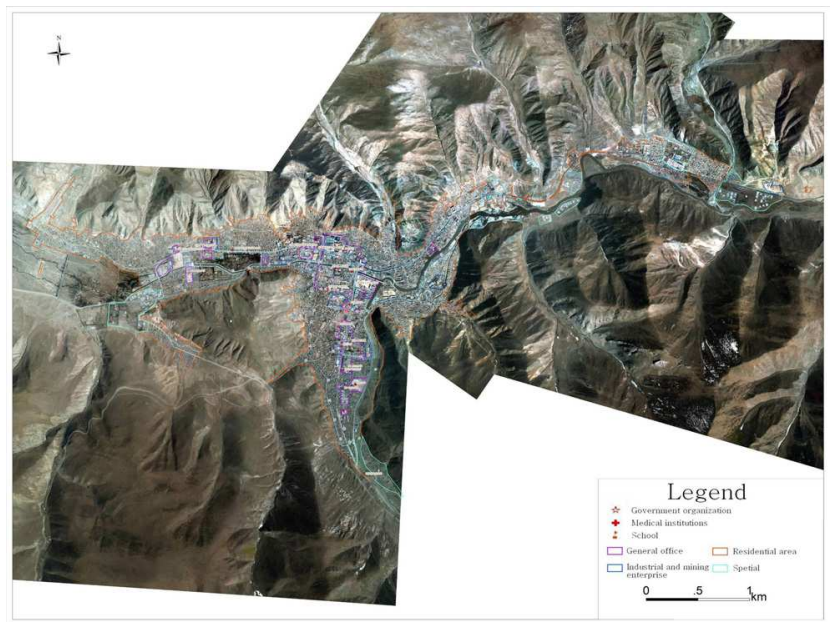

Fig. 15. Grids of first level

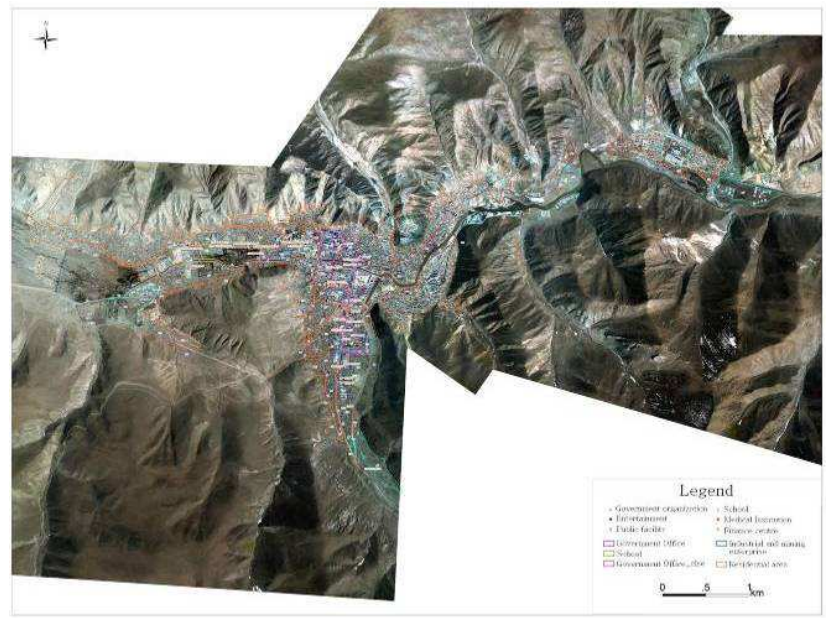

Fig. 16. Grids of second level 


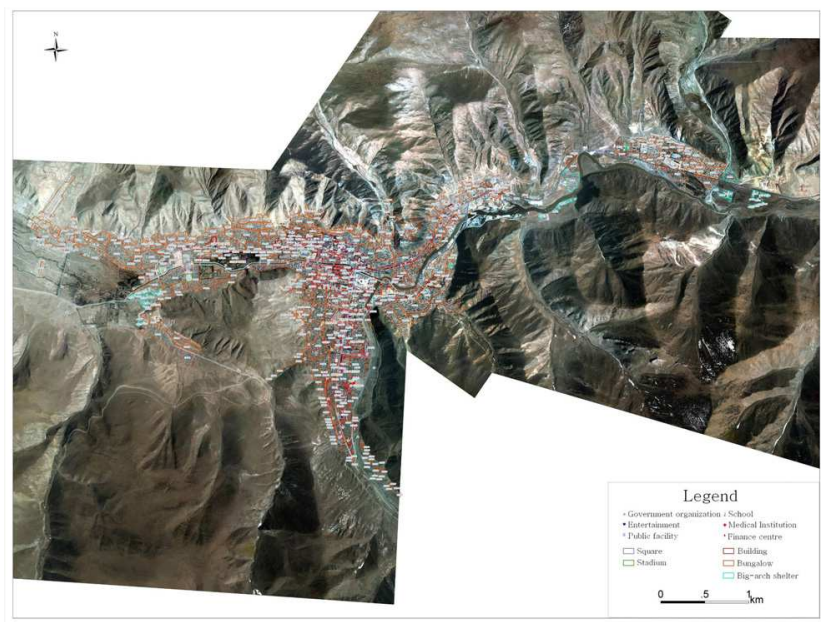

Fig. 17. Grids of third level

Hazard assessment expert group was then sent for field investigation. Damage extent, building size, architecture style, and actual pictures of each third level grid were collected and sent back to experts in NDRCC for interpretation and verification.

\subsubsection{Disaster monitoring}

At the same time, some key areas were monitored 24 hours a day using satellite and UAV images, including landslide region in Road 214, traffic jams in Road 308, refugee settlements area, terrain.

According to UAV monitoring images of $0.2 \mathrm{~m}$ in Figure 18, 9861 refugee tents were placed in Jiegu urban region by April 19th 5 days after the quake.

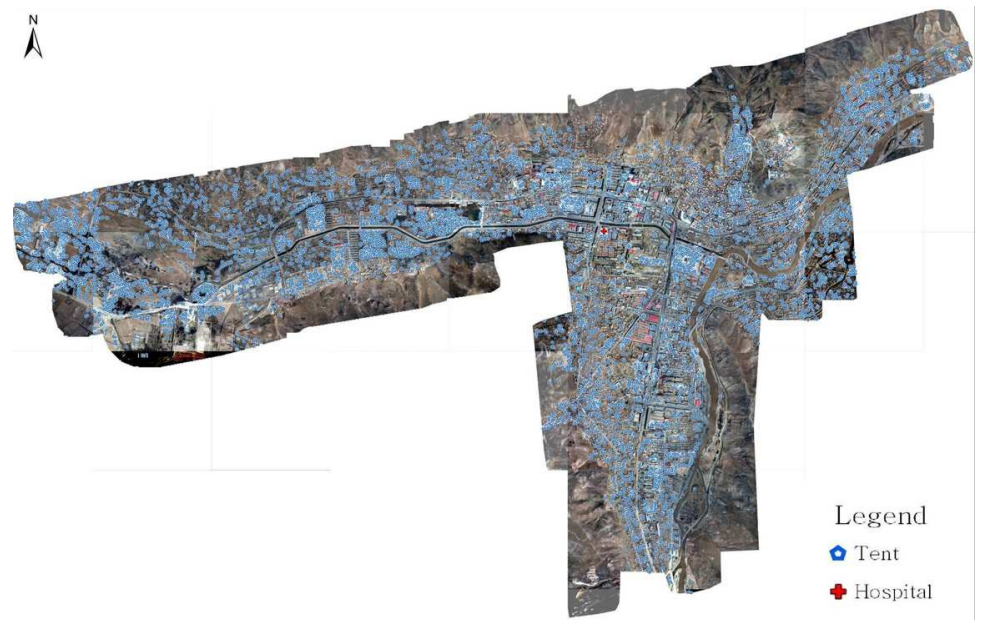

Fig. 18. Tent settlement monitoring 
26 landslide regions were spotted, among which 5 were along Road 214 in the south of Jiegu town, which resulted in traffic jam. The other 21 were mainly located in mountain region and had little affect to traffic. Figure 19 illustrates traffic jam caused by landslide along Road 214.

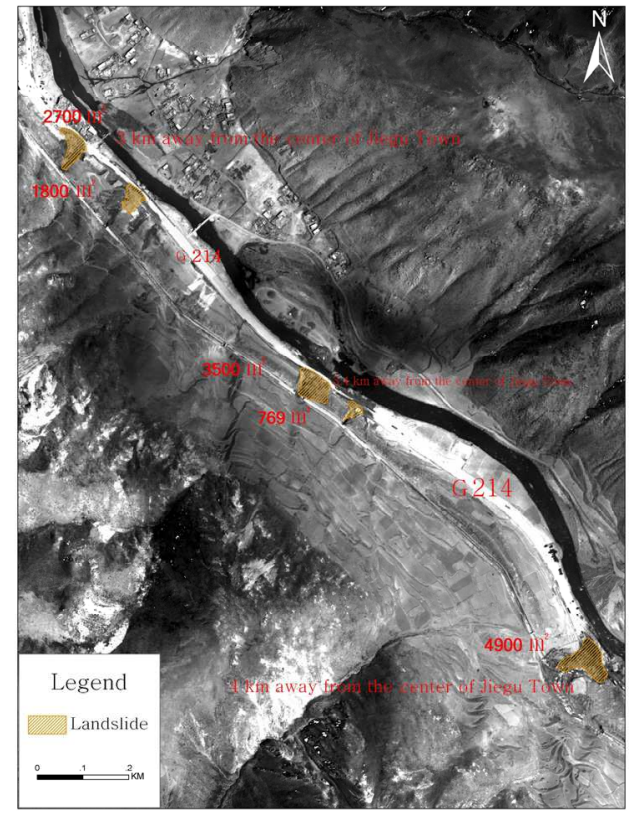

Fig. 19. Traffic jam monitoring and assessment in landslide regions

\subsubsection{Disaster scope assessment results}

Figure 20 illustrates CDI about the disaster scope and extent of loss. CDI for this case is a little different compared to that of previous Wenchuan Earthquake. For serious regions covering around $992 \mathrm{~km}^{2}$, CDI was 1; for severe regions of around $7030 \mathrm{~km}^{2}$, CDI was [0.2,1]; for general regions of $27840 \mathrm{~km}^{2}$, CDI was [0.01,0.2].

\subsubsection{Housing damage assessment results}

The housing damage scope and extent of loss were defined again by integrating field investigation data, data reported by local government (Figure 21). This is the first time satellite-airplane-ground integration assessment mode used in national disaster assessment. The damage scope was partitioned into three parts: collapsed building area, about 1,314,000 $\mathrm{m}^{2}$; serious damaged building area, about 2,332,000 $\mathrm{m}^{2}$; and minor damaged building area, about $680,000 \mathrm{~m}^{2}$. Collapsed building is defined as houses collapsed into ruins; serious damaged building as structures of houses been destroyed, thus it must be reconstructed; minor damaged building as structure been slightly affected, and it can still be used after reinforcement. Figure 8 and table 1 show housing damage assessment results. Figure 22 illustrates the remote sensing hazard monitoring and assessment flow in Yushu Earthquake. 


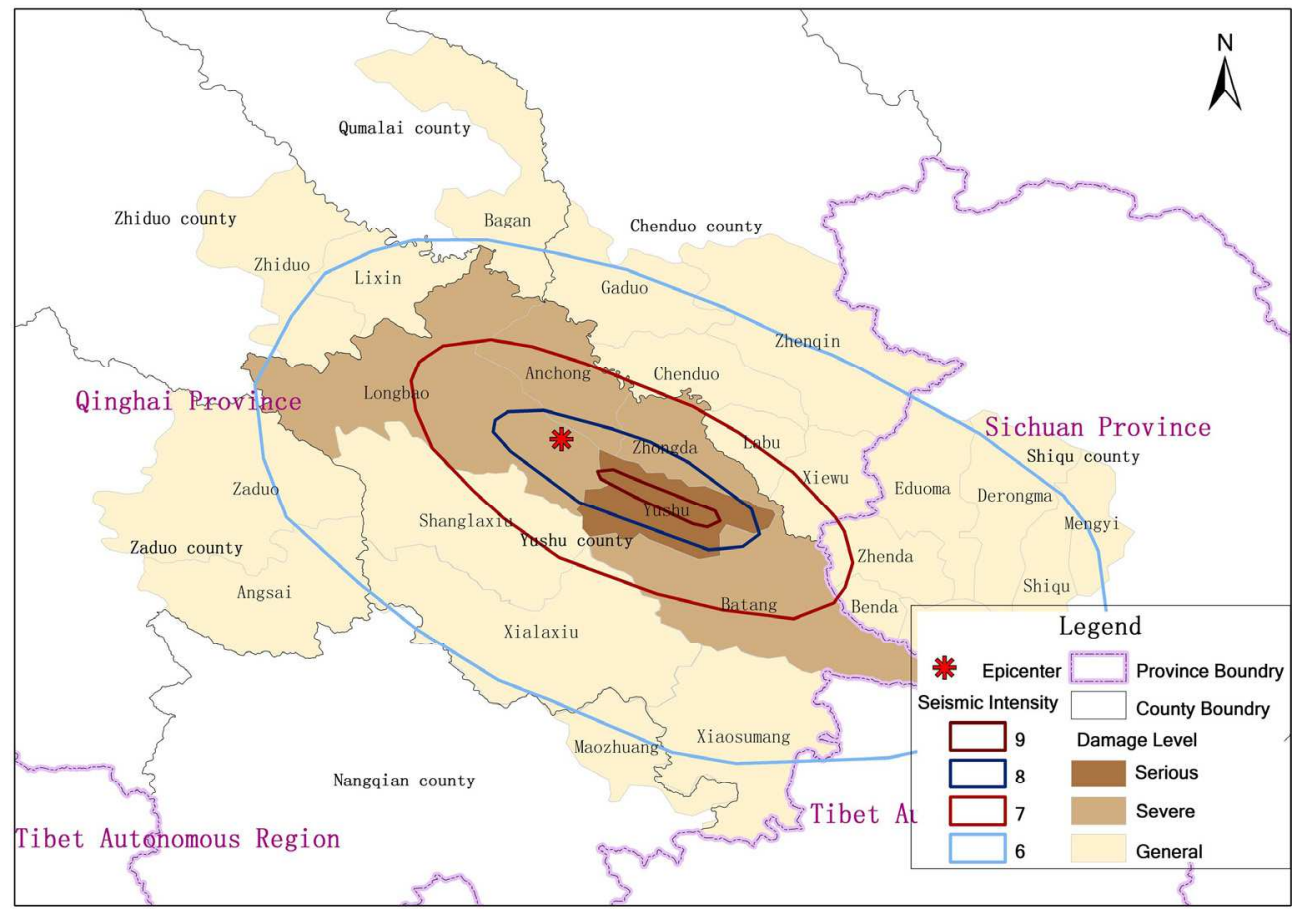

Fig. 20. Disaster scope assessment map of Yushu Earthquake

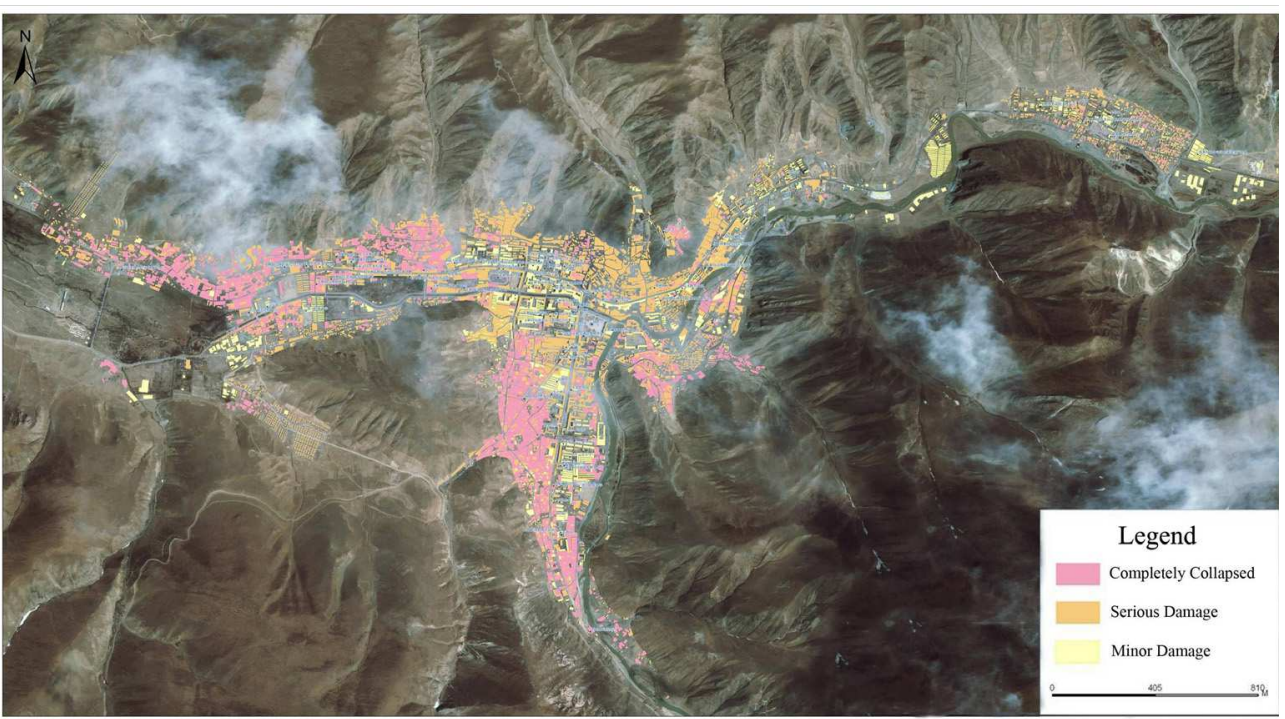

Fig. 21. Housing damage assessment results 


\begin{tabular}{|c|c|c|c|c|c|c|c|c|c|c|c|c|}
\hline \multirow{2}{*}{$\begin{array}{l}\text { Gollapse \& } \\
\text { tamage } \\
\text { type }\end{array}$} & \multicolumn{4}{|c|}{$\begin{array}{l}\text { Completely collapsed (ten } \\
\text { thousand square meters, \%) }\end{array}$} & \multicolumn{4}{|c|}{$\begin{array}{c}\text { Serious damage (ten thousand } \\
\text { square meters, } \% \text { ) }\end{array}$} & \multicolumn{4}{|c|}{$\begin{array}{c}\text { Minor damage (ten thousand } \\
\text { square meters, \%) }\end{array}$} \\
\hline & $\begin{array}{c}\text { Bungalo } \\
\mathrm{w}\end{array}$ & $\begin{array}{c}\text { Buildi } \\
\text { ng }\end{array}$ & Total & Ratio & $\begin{array}{c}\text { Bungal } \\
\text { ow }\end{array}$ & $\begin{array}{c}\text { Buildin } \\
\mathrm{g}\end{array}$ & Total & Ratio & $\begin{array}{c}\text { Bungal } \\
\text { ow }\end{array}$ & $\begin{array}{c}\text { Buildin } \\
\mathrm{g}\end{array}$ & Total & Ratio \\
\hline Residential & 118.5 & 1.6 & 120.1 & 27.8 & 116.6 & 31.2 & 147.8 & 34.2 & 27.7 & 8.5 & 36.2 & 8.4 \\
\hline Office & 0.8 & 4.9 & 5.7 & 1.3 & 3.8 & 62.7 & 66.5 & 15.3 & 4.2 & 17.3 & 21.5 & 4.9 \\
\hline School & 0.7 & 0 & 0.7 & 0.2 & 0.2 & 1.4 & 1.6 & 0.4 & 0 & 0.9 & 0.9 & 0.2 \\
\hline $\begin{array}{c}\text { Industrial } \\
\text { and mining } \\
\text { enterprises }\end{array}$ & 0.1 & 0.5 & 0.6 & 0.1 & 2.2 & 4.8 & 7 & 1.6 & 0.6 & 2.9 & 3.5 & 0.8 \\
\hline Special & 4 & 0.2 & 4.2 & 1.0 & 8.9 & 1.4 & 10.3 & 2.4 & 5.4 & 0.5 & 5.9 & 1.4 \\
\hline Total & 124.1 & 7.3 & 131.4 & 30.4 & 131.7 & 101.5 & 233.2 & 53.9 & 37.9 & 30.1 & 68 & 15.7 \\
\hline
\end{tabular}

Table 2. Housing damage construction area statistic table of Jiegu town urban area.

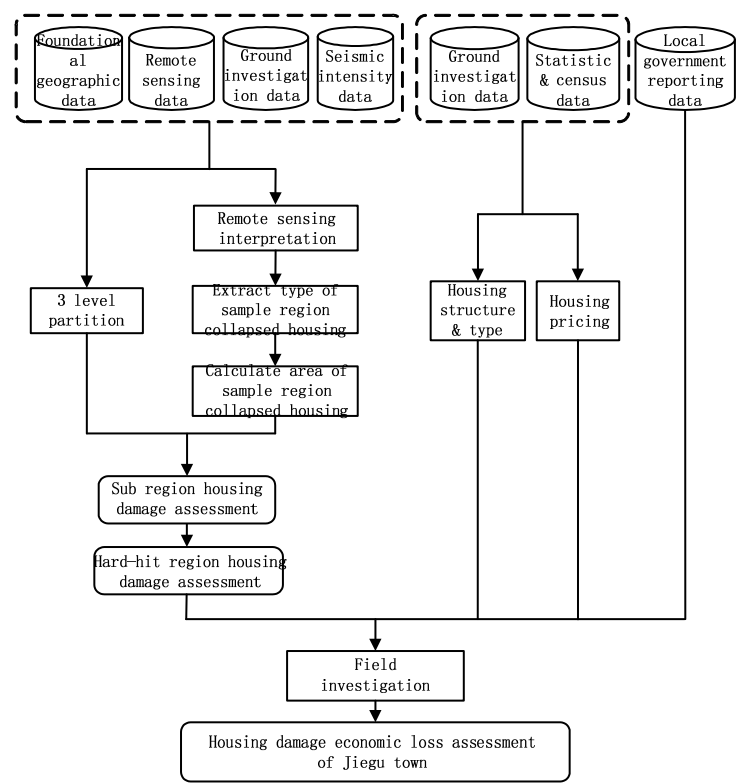

Fig. 22. Remote sensing hazard monitoring and assessment flow

\subsection{Zhouqu debris flow}

On August $8^{\text {th }}$ 2010, a serious debris flow disaster occurred in Zhouqu County, Gannan Tibetan Autonomous Prefecture, Gansu Province, and China. The debris flow breaks many records since 1949, including number of death, extent of damage, and relief difficulty. The casualty consists of 1447 deaths, 318 missing, and about 21000 residents were forced to evacuate by p.m.4, August $24^{\text {th }}$. The disaster lasted for a long time, and repeatedly occurred in some regions, resulting in several barrier lakes, and part of town under water. After $8^{\text {th }}$, the disaster area had suffering from several heavy rains, which, triggered more debris flow, and interrupted the traffic. The hard-hit region was in remote mountain area with narrow road, making disaster relief a very difficult task. 


\subsubsection{Preliminary assessment}

An UAV and airplane were sent to Zhouqu one day after the debris to acquire affected area images, including UAV image of $0.2 \mathrm{~m}$ resolution and aerial remote sensing images of $1 \mathrm{~m}$ resolution. Once the images were sent back, we compared pre-disaster and post-disaster remote sensing images, continually monitored disaster scope, damage extent of housing, residents, variation of river water level, newly happened landslide, and preliminary analyzed and estimated the damage condition and disaster trend.

Figure 23 illustrates preliminary assessment result. Collapsed area was $0.14 \mathrm{~km}^{2}$, among which more than $90 \%$ were bungalows; serious damaged area was $0.15 \mathrm{~km}^{2}$, among which more than $79 \%$ were buildings; minor damaged area was $1.12 \mathrm{~km}^{2}$, among which more than $40 \%$ were buildings. Affected crop area was about $0.45 \mathrm{~km}^{2}$, and affected forest area was about $0.27 \mathrm{~km}^{2}$.

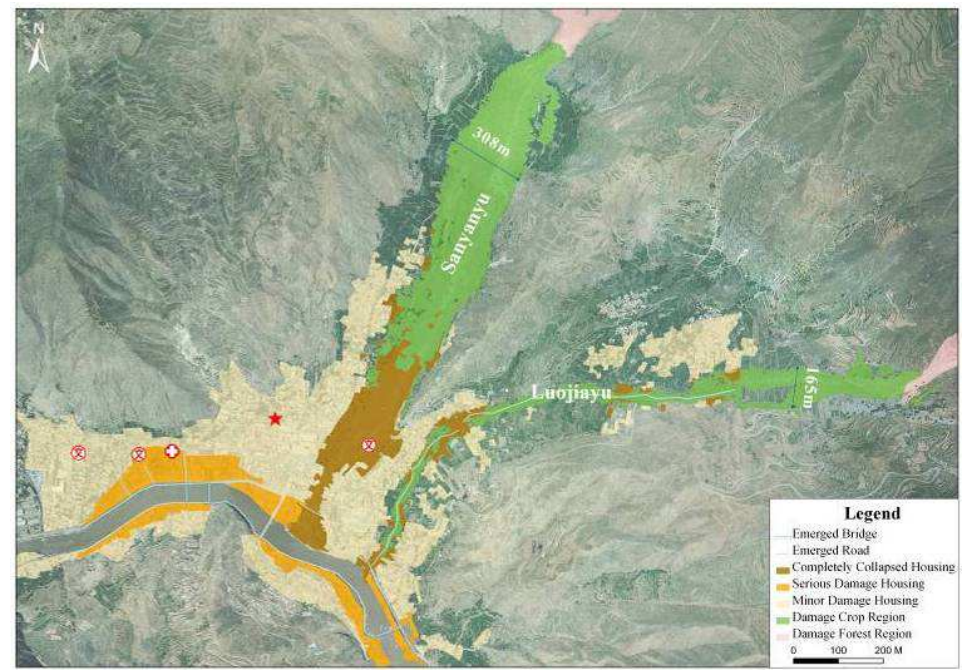

Fig. 23. Preliminary assessment results of Zhouqu Debris Flow disaster

According to debris flow and landslide monitoring result (Figure 24), Sanyanyu debris flow area was $0.66 \mathrm{~km}^{2}$; Luojiayu debris flow area was $0.2 \mathrm{~km}^{2}$. The 5 landslide regions in the mountain area of Zhouqu had a total area of $17272 \mathrm{~km}^{2}$.

Figure 25 and Table 3 shows refugee settlement monitoring result. Tents number increased a lot from August $15^{\text {th }}$ to August $8^{\text {th }}$.

\begin{tabular}{|c|c|c|c|c|}
\hline Settlement & Area $\left(\mathrm{m}^{2}\right)$ & $\begin{array}{c}\text { Tents number in } 8^{\text {th }} \\
\text { August }\end{array}$ & $\begin{array}{c}\text { Tents number in } \\
15^{\text {th }} \text { August }\end{array}$ & Increasing number \\
\hline No.1 high school & 2079 & 13 & 55 & 42 \\
\hline No.3 high school & 3590 & 36 & 98 & 62 \\
\hline total & 5669 & 49 & 153 & 104 \\
\hline
\end{tabular}

Table 3. Comparison of tents number 


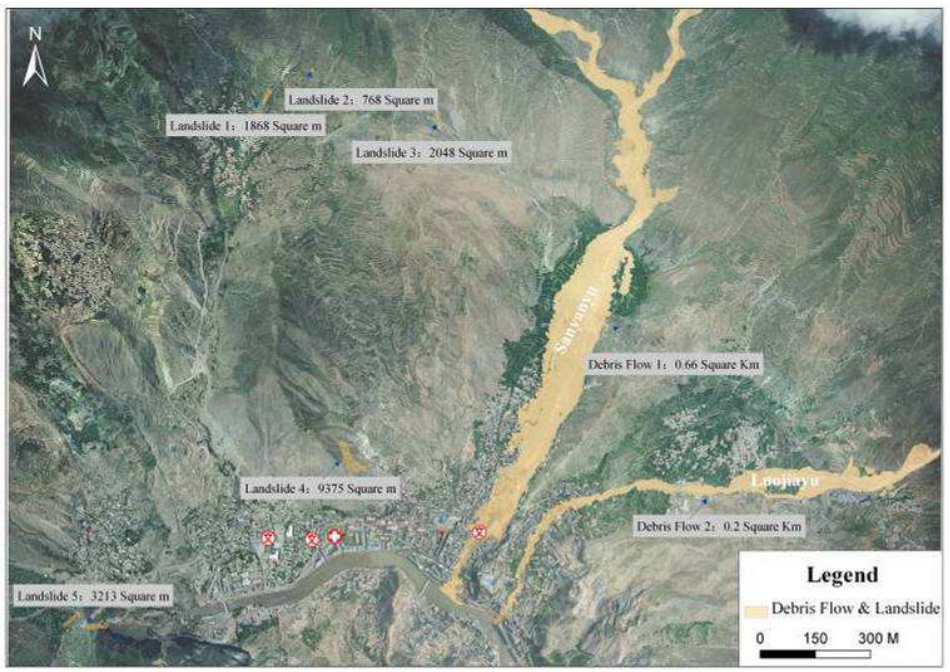

Fig. 24. Debris flow and landslide monitoring map

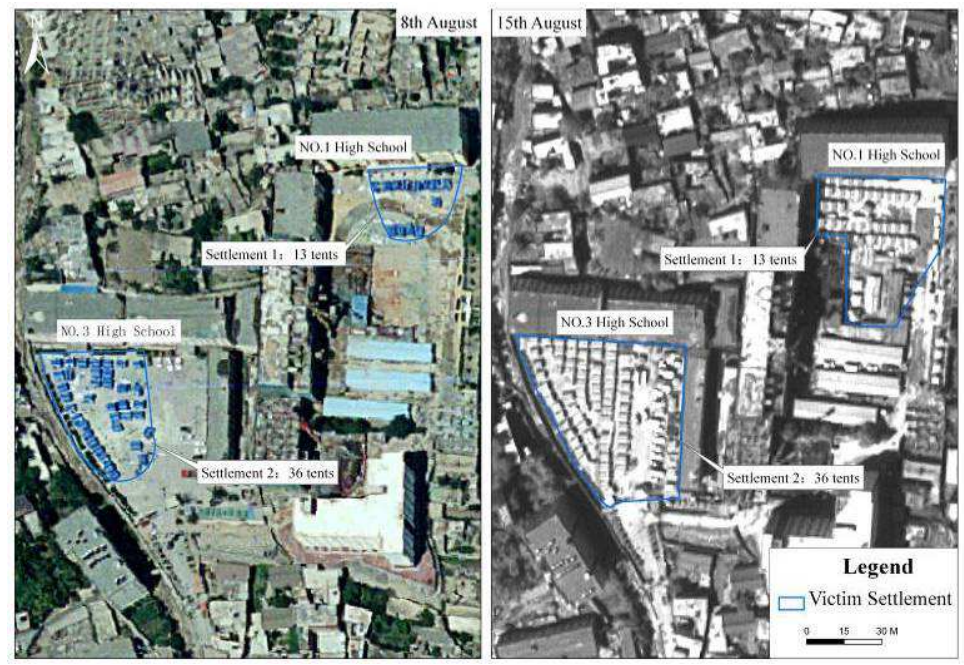

Fig. 25. Settlement monitoring map

The flooded area expanded obviously (Figure 26), with about 226,000 $\mathrm{m}^{2}$ in August $15^{\text {th }}$, $23,000 \mathrm{~m}^{2}$ more compared with that in August $10^{\text {th }}$, and $102,000 \mathrm{~m}^{2}$ more compared with that in May $5^{\text {th }}$. 


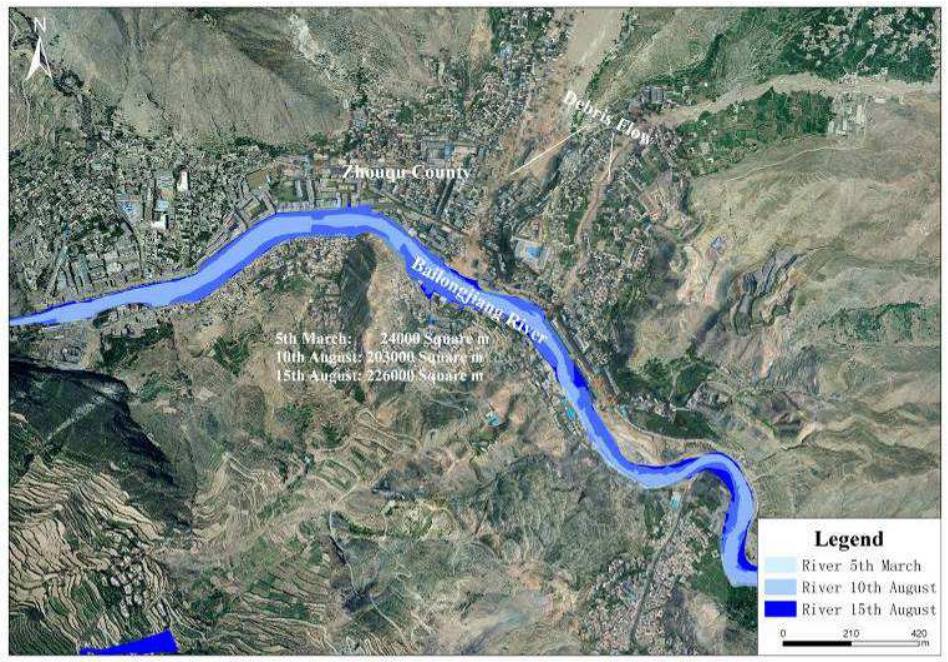

Fig. 26. Water area monitoring map

\subsubsection{Ground investigation}

Then according to the preliminary analysis results, we partitioned affection area into 2-level grids similar with previous case, using house as unit in high-resolution UAV and airborne remote sensing images. A total of 2457 girds were indexed (Figure 27). Hazard assessment experts were sent for field investigation. The damage extent, building size, architectural style, and field pictures of each grid were collected and sent back to experts in NDRCC for interpretation and verification.

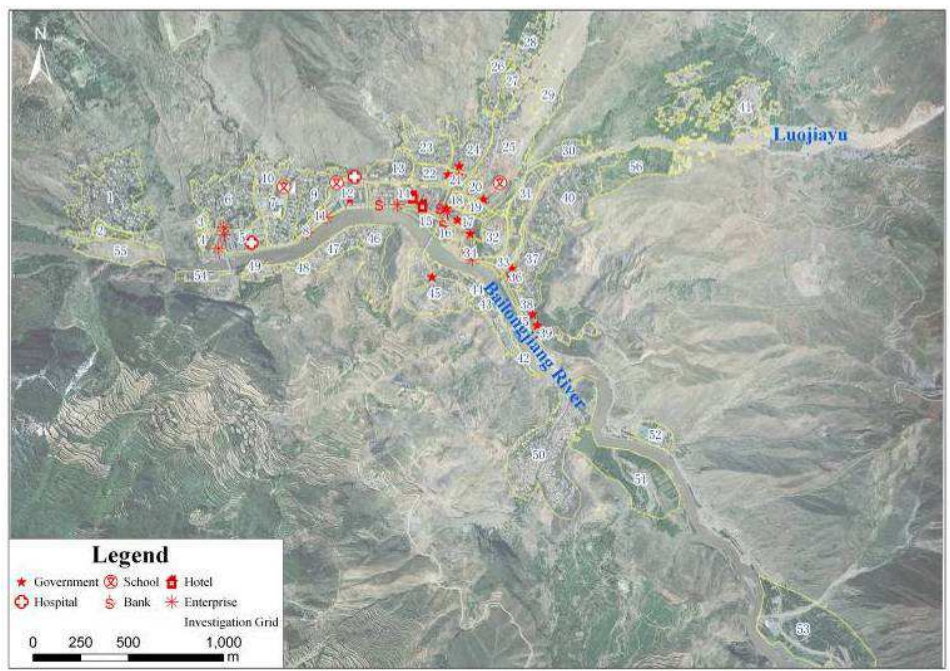

Fig. 27. Field investigation grids partition map 
First level includes 3 categories of 59 grids: seriously damaged area, seriously flooded area, and minor affect area; Second level includes 2457 subgrids.

\subsubsection{Disaster scope and housing damage assessment}

The disaster scope and damage extent were defined again by integrating pre-disaster, postdisaster remote sensing information, ground investigation data and data reported by local government (Figure 28).

Disaster area was partitioned into three parts: serious affected region refers to the regions which bore main force of landslide, resulting in serious damage to houses, infrastructure and farmland; severe affected area refers the region which suffered from a long time soaked in water and mud, causing damage to houses; minor affected region refers to the region where houses and infrastructures are mildly damaged by floods and landslides.

The serious affected area was $1.2 \mathrm{~km}^{2}$, severe affected area was $0.2 \mathrm{~km}^{2}$ and minor affected area was $1.0 \mathrm{~km}^{2}$.

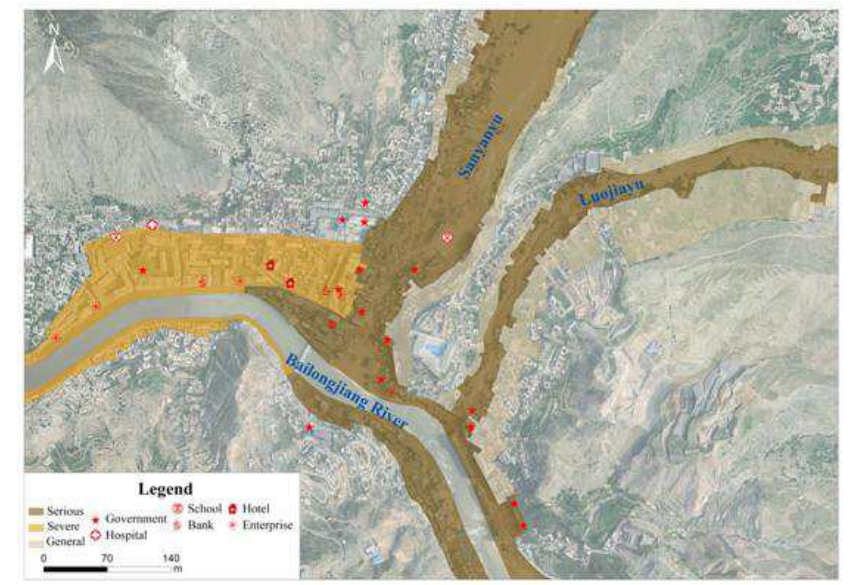

Fig. 28. Disaster scope assessment map of Zhouqu debris flow disaster

\subsubsection{Physical quantity assessment}

In the following Physical Quantity Assessment process, with the help of data reported by local government, we carefully assessed the physical quantity of houses, roads, power facilities, communication facilities, water conservation facilities, municipal utilities and land resources in UAV and airborne images to estimate approximate direct economic loss. It is worth to mention that some damage quantity ignored in field investigation was detected in remote sensing images, such as submerse street trees, telegraph poles, smart street pavilions.

According to remote sensing images and ground investigation verification result (Figure 29), in rush destroyed region, collapsed residential building area was about $125,000 \mathrm{~m}^{2}$, seriously damaged area was about 102,000 m², minor damaged area was about 147,000 m². In flooded region, collapsed building area was around 419,827 $\mathrm{m}^{2}$. 


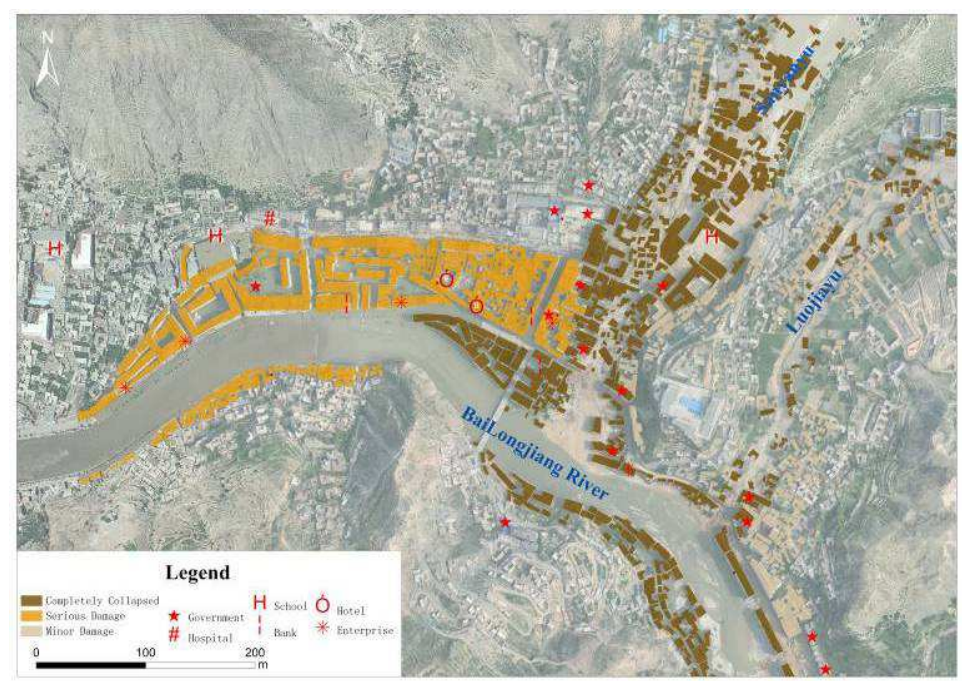

Fig. 29. Housing damage assessment map

Roads were divided into 3 classes (Figure 30): provincial road, urban road and rural road. According to remote sensing assessment result, 2 provincial roads were damaged, with a length of $2 \mathrm{~km}$; 25 urban roads were damaged, with a length of $7.5 \mathrm{~km} ; 5$ rural roads were damaged, with a length of $4.8 \mathrm{~km}$. Three bridges of a total length of 242 meters were out of function.

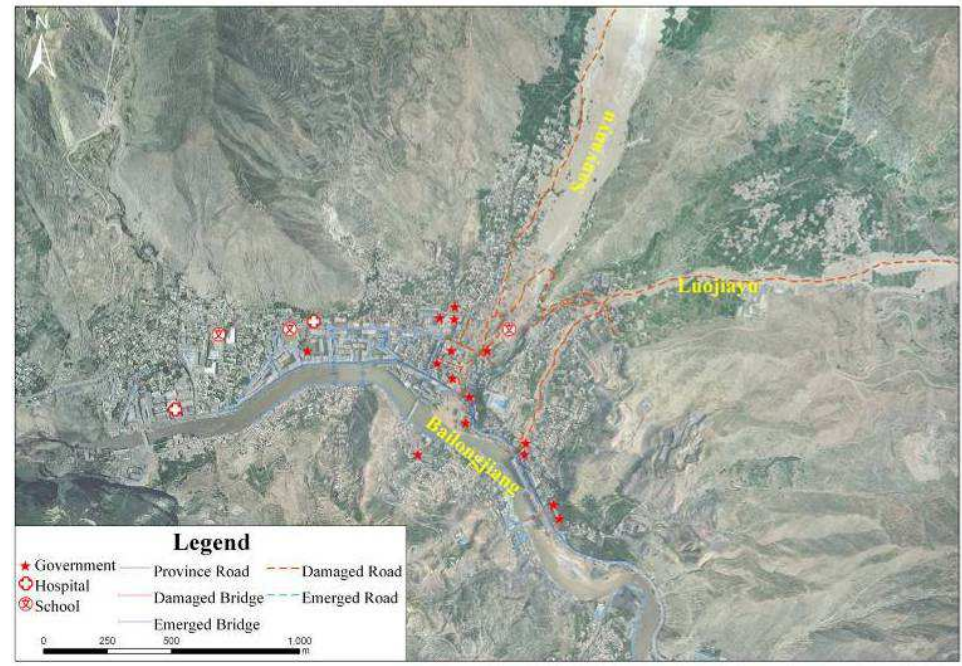

Fig. 30. Road and bridge damage assessment map

The physical quantity assessment results were used for direct economic losses estimation. It is for the first time for China that remote sensing images are integrated into the national catastrophe assessment flow as a major data source. 


\section{Conclusion}

Throughout the three cases discussed in this chapter, one interesting thing is that the importance of remote sensing images is increasing in the whole process of disaster assessment: preliminary assessment step, disaster scope and damage assessment step, and physical quantity assessment. Also, the resolution of remote sensing images is improved, from $0.5 \mathrm{~m}$ to $0.2 \mathrm{~m}$, providing more accurate data for assessment and decision making.

Although the whole process of integration of remote sensing images and data from ground investigation has been growing mature, the sample region choosing, physical quantity assessment still need further improvement.

Another thing to notice is that, automatic operation system is needed to connect the whole disaster assessment flow to provide efficient and accurate data for decision making. The satellite-airplane-ground disaster monitoring and assessment system is the trend we are and will realize in the near future.

\section{Acknowledgment}

This chapter is sponsored by High Resolution Earth Observation System Project of China.

\section{References}

Chen, S.; Ma, H. \& Fan, Y. et al. (2008). Road Damage Assessment from High Resolution Satellite Remote Sensing Imagery in Wenchuan Earthquake. Journal of Remote Sensing, Vol.12, No.6, pp. 949-955, ISSN 1007-4619.

Fan, Y.; Yang, S. \& Wang, L. et al. (2008a). Study on Urgent Monitoring and Assessment in Wenchuan Earthquake. Journal of Remote Sensing, Vol.12, No.6, pp. 858-864, ISSN 1007-4619.

Fan, Y.; Yang, S. \& Wang, W. et al. (2008b). Comprehensive Assessment of Disaster Scope, In:Comprehensive Analysis and Assessment of Wenchuan Earthquake, Zhu, H., pp. (94103), Science Press, ISBN 978-7-03-023855-9, Beijing, China.

Shi, F.; He, H.; Zhang, Y. (2010). Remote Sensing Interpretation of the MS7.1 Yushu Earthquake Surface Ruptures, Technology for Earthquake Disaster Prevention, Vol.5, No.2, pp. 220-227, ISSN 1673-5722.

The sixth editing room of Press of China Standards (2010). Compilation of Earthquake and Related Standards, Press of China Standards, ISBN 978-7-5066-5651-1, Beijing, China.

Wen, Q.; He H. \& Wang X. et al. (2011). UAV remote sensing hazard assessment in Zhouqu Debris Flow Disaster, Proceedings of SPIE European Remote Sensing, ISBN 9780819488022, Prague, Czech Republic, September, 2011.

Xie, L.; Zhang, J. (2000). Application of Satellite Remote Sensing Technology in Earthquake Disaster Reduction, Journal of Natural Disasters, Vol.9, No.4, pp. 1-8, ISSN 1004-4574.

Yang, S.; Liu, S. \& Wu, W. et al. (2011). Remote Sensing Applications in Qinghai Yushu Earthquake Monitoring and Assessment, Spacecraft Engineering, Vol.20, No.6, pp. 90-96, ISSN 1673-8748. 
Zhang, D. (1993). Preliminary Study on Visual Interpretation Marks of Building Damages Caused by Earthquakes on Aero Photograph, Earthquake, Vol.13, No.1, pp. 26-30, ISSN 1000-3274. 


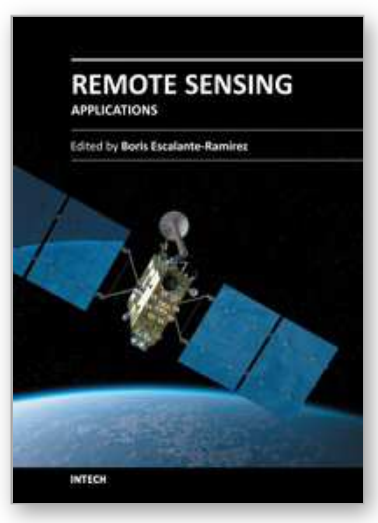

\author{
Remote Sensing - Applications \\ Edited by Dr. Boris Escalante
}

ISBN 978-953-51-0651-7

Hard cover, 516 pages

Publisher InTech

Published online 13, June, 2012

Published in print edition June, 2012

Nowadays it is hard to find areas of human activity and development that have not profited from or contributed to remote sensing. Natural, physical and social activities find in remote sensing a common ground for interaction and development. This book intends to show the reader how remote sensing impacts other areas of science, technology, and human activity, by displaying a selected number of high quality contributions dealing with different remote sensing applications.

\title{
How to reference
}

In order to correctly reference this scholarly work, feel free to copy and paste the following:

Qi Wen, Yida Fan, Siquan Yang, Shirong Chen, Haixia He, Sanchao Liu, Wei Wu, Lei Wang, Juan Nie, Wei Wang, Baojun Zhang, Feng Xu, Tong Tang, Zhiqiang Lin, Ping Wang and Wei Zhang (2012). High Resolution Remote Sensing Images Based Catastrophe Assessment Method, Remote Sensing - Applications, Dr. Boris Escalante (Ed.), ISBN: 978-953-51-0651-7, InTech, Available from: http://www.intechopen.com/books/remotesensing-applications/high-resolution-remote-sensing-images-based-catastrophe-assessment-method

\section{INTECH}

open science | open minds

\section{InTech Europe}

University Campus STeP Ri

Slavka Krautzeka 83/A

51000 Rijeka, Croatia

Phone: +385 (51) 770447

Fax: +385 (51) 686166

www.intechopen.com

\section{InTech China}

Unit 405, Office Block, Hotel Equatorial Shanghai

No.65, Yan An Road (West), Shanghai, 200040, China

中国上海市延安西路65号上海国际贵都大饭店办公楼 405 单元

Phone: +86-21-62489820

Fax: +86-21-62489821 
(C) 2012 The Author(s). Licensee IntechOpen. This is an open access article distributed under the terms of the Creative Commons Attribution 3.0 License, which permits unrestricted use, distribution, and reproduction in any medium, provided the original work is properly cited. 